\title{
High expression level and nuclear localization of Sam68 are associated with progression and poor prognosis in colorectal cancer
}

\author{
Wen-Ting Liao ${ }^{1,3+}$, Jun-Ling Liu ${ }^{4+}$, Zheng-Gen Wang ${ }^{5+}$, Yan-Mei Cui ${ }^{1,3}$, Ling Shi ${ }^{2}$, Ting-Ting Li
} Xiu-Ting Chen ${ }^{2}$, Yan-Qing Ding ${ }^{1,3^{*}}$ and Li-Bing Song ${ }^{2^{*}}$

\section{Abstract}

Background: Src-associated in mitosis (Sam68; $68 \mathrm{kDa}$ ) has been implicated in the on enesis and progression of several human cancers. The aim of this study was to investigate the clinicopath pgic sig/ificance of Sam68 expression and its subcellular localization in colorectal cancer (CRC).

Methods: Sam68 expression was examined in CRC cell lines, nine matched Ch tissues and adjacent noncancerous tissues using reverse transcription (RT)-PCR, quantitative RT-PCR and $V$ blotting. Sam68 protein expression and localization were determined in 224 paraffin-embedded archived (BR Samples using immunohistochemistry. Statistical analyses were applied to evaluate the clinicopatholoaic signifi ance.

Results: Sam68 was upregulated in CRC cell lines and CP as a pared with normal tissues; high Sam68 expression was detected in 120/224 (53.6\%) of the CRC tis. S. H th Sam68 expression correlated significantly with poor differentiation $(P=0.033)$, advanced T stage $(P<0.001)$, ,age $(P=0.023)$ and distant metastasis $(P=0.033)$. Sam68 nuclear localization correlated significant $b$ poo differentiation $(P=0.002)$ and T stage $(P=0.021)$. Patients with high Sam68 expression or Sam 8 nuclè ofalization had poorer overall survival than patients with low Sam68 expression or Sam68 cytoplasn iic alization. Patients with high Sam68 expression had a higher risk of recurrence than those with low Sam68 upressic

Conclusions: Overexpression of San 68 correlated highly with cancer progression and poor differentiation in CRC. High Sam68 expression and Sam68 clear localization were associated with poorer overall survival.

Keywords: Sam68, Biomarker, nanosis, Colorectal cancer

\section{Background}

Colorectal cancer CI the most prevalent malignancies $\mathrm{w}$ ldwide. though advances have been made in dis ano and therapeutic techniques, the prognosis on CRC $\mathrm{P}$ ents with distant metastases still remain od [1]. Thus, characterization of the molecular mecha $\mathrm{m}^{\mathrm{t}}$ at involves in progression and metastasis o CRC suld help to identify specific biomarkers

* Corr Jndence: dyq@fimmu.com; lb.song1@gmail.com

${ }^{\dagger}$ Equal contributors

'Department of Pathology, Nanfang Hospital, Southern Medical University, Guangzhou, Guangdong 510515, China

${ }^{2}$ State Key Laboratory of Oncology in Southern China, Department of Experimental Research, Sun Yat-sen University Cancer Center, Guangzhou, Guangdong 510060, P.R. China

Full list of author information is available at the end of the article which may facilitate efficient therapeutic stratification, prediction and disease prevention.

Src-associated in mitosis, $68 \mathrm{kDa}$ (Sam68) belongs to the signal transduction and activation of RNA (STAR) family of $\mathrm{K}$ homology $(\mathrm{KH})$ domain-containing RNA binding proteins [2] and is originally identified as a substrate for Src kinase phosphorylation during mitosis [3,4]. Sam68 is ubiquitously expressed and plays important roles in signaling transduction, gene transcription, and alternative splicing [2,5]. Sam68 has been suggested to act as an adaptor in signal transduction by binding to SH3- and $\mathrm{SH} 2$-containing proteins, through its proline-rich regions [6]. Additionally, Sam68 can interact with signaling proteins, such as Src, Grb2, Grap, SHP-1, PLC 1 1/Fyn, BRK and PI3K, and has been implicated in T-cell receptor and 
insulin receptor signaling, as well as Ras and PI3K kinase pathways [7-11]. Moreover, Sam68 is usually a nuclear protein and plays a major role in the regulation of RNA metabolism, including mRNA transcription, alternative splicing and nuclear export [12-17]. The alternative splicing of multiple genes regulated by Sam68, including those involved in oncogenesis, such as CD44, Bcl-xl, Sgce, SMN2, SF2/ASF and Cyclin D1 [6,14-19].

The above mentioned biological functions of Sam68 closely linked this protein to oncogenic properties. First, Sam68 is involved in promotion of cell cycle progression, cell proliferation, transformation, tumorigenesis and metastasis in different cellular context [20-25]. Second, a series of published articles in the recent decade have demonstrated that Sam68 participates in transcriptional and post-transcriptional regulation of gene expressions that are relevant to human cancer $[14,15,17,18,20,26]$. However, deregulation of Sam68 in human cancer tissues has only been observed in limited cancer types, including prostate cancer, renal cell carcinoma, breast and cervical cancer [23,24,26-28]. Whether the deregulation of Sam68 is a prevalent event in human cancer needs further investigation. To explore the deregulation of Sam68 in human colorectal cancer, we investigated the expression patterns of Sam68 in human CRC tissues, and the correlation between Sam68 expression levels and the clinicopathologic features of CRC. Our current study indicates that e pression and localization of Sam68 may act as indep ent biomarkers of prognosis in CRC, su of ting thi Sam68 has potential as a novel therapeutic targ ${ }^{\prime}$ or the treatment of CRC.

\section{Methods}

\section{Cell lines}

Colorectal cancer cell lines incluc.... LS174t, Colo205, SW480, HT29, HCT116 SW620 cells were cultured in RPMI 1640 (Invitroge Car had. CA, USA) supplemented with $10 \%$ fetal boye st $\eta$, $100 \mu \mathrm{g} / \mu \mathrm{L}$ streptomycin and $100 \mu \mathrm{g} / \mu \mathrm{L}$ pen $\mathrm{n}$ in a $\mathrm{l}$, midified incubator containing $5 \% \mathrm{CO}_{2}$ at $37 \mathrm{C}$.

\section{Patiencs d issule specimens}

For he us of clinical materials for research purposes, rior atients consents and approval were obtained from th. Sur rat-sen University and Cancer Center Institutiona oard. All samples were collected and analyzed with prior written informed consents from the patients. A total of 224 paraffin-embedded colorectal cancer samples, which were histopathologically and clinically diagnosed at the Sun Yat-sen University Cancer Center between the year 2000 to 2003, were examined. All of the patients had received chemotherapy after surgery. Prior patient consent and approval were obtained from the Institutional Research Ethics Committee.
The clinicopathological features of the patients are summarized in Additional file 1: Table S1. The final study population included 97 female and 127 male patients (age range, 23-82 years). Follow-up was recorded from the date of surgery until death. Patients who died of cancer (or other causes) were classified as dear The median follow-up time for all patients was 58.47 menths. 43 corresponding metastatic lymph nodes a aso obtained from the above mentioned patients. Foun is of CRC biopsies and the matched djacen noncancerous colon tissues were obtain u fron $\mathrm{cb}$ patient during surgery, and immediately rozen and, naintained in liquid nitrogen until further us

RNA extraction, reverse tanscrip n-polymerase chain reaction and quantitative sal-time polymerase chain reaction

Total RNA wa e $\mathrm{e}$ acted fom the cultured cells and surgical tissuc TRIzol reagent (Invitrogen) according to the anufacturer's instructions. Reverse transcript nolymerase chain reaction (RT-PCR) and quantitative rea -time polymerase chain reaction (QPCR) analy is of Sam68 expression were performed as Pr usly described [29], using previously published vrim s and probes [28]. Sam68 expression was analyzed ng the $2^{-\Delta \Delta C t}$ method as described by Livak et al. [30] and normalized to the geometric mean expression level of the housekeeping gene glyceraldehyde-3-phosphate dehydrogenase (GAPDH). The relative change in Sam68 expression was calculated by pair-wise comparison of the normalized Sam68 expression level in the tumor samples with the adjacent non-cancerous tissue samples from the same patient.

\section{Western blotting}

Tissue and cell lysates were prepared using SDS lysis buffer and the protein concentration was determined using the Bradford assay (Bio-Rad Laboratories, Hercules, CA, USA). Equal amounts of protein were separated by electrophoresis on a $10.5 \%$ sodium dodecyl sulfate polyacrylamide gel and electrotransferred from the gel to a nitrocellulose membrane. After blocking with 5\% milk solution in Tris-buffered saline with Tween (TBST) for 1 hour, the membrane was incubated with primary antibody against rabbit antibody Sam68 (sc-333, dilution, 1:500; Santa Cruz Biotechnology, CA, USA) and rabbit anti- $\alpha$-Tubulin (1:1000, Sigma, Saint Louis, MI, USA) primary antibodies. After washing with TBS-T, the membrane was incubated with secondary antibody against rabbit immunoglobulin $G$ or mouse immunoglobulin G; then, it was examined with the enhanced chemiluminescence detection system (Amersham Biosciences Europe, Freiberg, Germany) according to the manufacturer's instructions. 


\section{Immunohistochemistry}

Paraffin sections were deparaffinized with xylene and rehydrated, then submerged into EDTA antigenic retrieval buffer and microwaved for antigenic retrieval. The sections were then treated with $3 \%$ hydrogen peroxide in methanol to quench the endogenous peroxidase activity, followed by incubation with 1\% BSA to block the non-specific binding. The sections were incubated with rabbit anti-Sam68 (sc-333, dilution, 1:500; Santa Cruz Biotechnology, CA, USA) overnight at $4^{\circ} \mathrm{C}$. As negative controls, rabbit anti-Sam68 antibody was replaced with normal goat serum, or the rabbit antiSam68 antibody was blocked by co-incubation with a recombinant Sam68 polypeptide at $4{ }^{\circ} \mathrm{C}$ overnight prior to the immunohistochemical staining. The staining intensity was scored on a scale of 0 to 3 as 0 (no staining), 1 (weak staining light yellow), 2 (moderate staining $\sim$ yellowish brown) or 3 (strong staining $\sim$ brown). Tumors with a staining intensity $\geq 2$ in which at least $50 \%$ of the malignant cells were Sam68-positive were classified as high expression; tumors with a staining intensity $<2$ or in which less than $50 \%$ of the malignant cell were Sam68-positive were classified as low expression.

\section{Statistical analysis}

All statistical analyses were carried out using SroS 10.0 (Chicago, IL, USA). The significance of the $\mathrm{ffe}$ ences between the normal and tumor tissue $C_{2}-\mathrm{PC}$ sults were assessed using the Student's two led $t$-tes. The association between Sam68 expression an inicopathological variables were assessed using the N,annWhitney U test. Survival curves ere plotted using the Kaplan-Meier method. The Cox oporional hazards regression model was for univariate and multivariate analysis. Two-tail d, dues $<0.05$ were considered significant

\section{Results}

Expression of Sam68 in colorectal cancer cell lines

We examined the expression of Sam68 using Western blotting in seven human colon cancer cell lines and two cases of normal intestine tissues. The results displayed that Sam68 protein expression level was much higher in CRC cell lines than that in normal intestir tissues (Figure 1A). We next measured the expression am68 mRNA in the CRC cell lines using RT-PCR (Figu and (Figure $1 C$ ). In agreement with the rotein xpression levels, the Sam68 mRNA express le el was much higher in CRC cell lines $\mathrm{t}^{\prime}$ an that in 1 ormal intestine tissues.

\section{Sam68 is upregulated in orimary 'man CRC lesions}

Western blotting and $\mathrm{K}$ PCR andyses were performed to determine the expressio f Sam68 in nine paired primary CRC tis sues and the matched adjacent noncancerous tiss at both the pro $\eta$ (Figure 2A) and mRNA levels (Figure 2 all nane of the CRC tissues tested, compared to the mo,ched adjacent normal tissues from the same patient, Q-PCR results confirmed that Sam68 m. A was upregulated in the tumor samples by up to 18.3- ld (Sam68 tumor/normal $[\mathrm{T} / \mathrm{N}]$ ratio; Figure 2C; 0,1 , Student's $t$-test).

In agreement with the Western blotting results, immunohistochemical analysis confirmed that Sam68 was overexpressed in all nine of the CRC tissues tested, compared with the paired adjacent normal tissues (Figure 2D). Taken together, these results indicated that Sam68 is upregulated in CRC lesions at both transcriptional and translational levels.

We further performed immunohistochemical analysis to determine the expression patterns of Sam68 in 224 paraffin-embedded CRC tissues and 43 lymph node
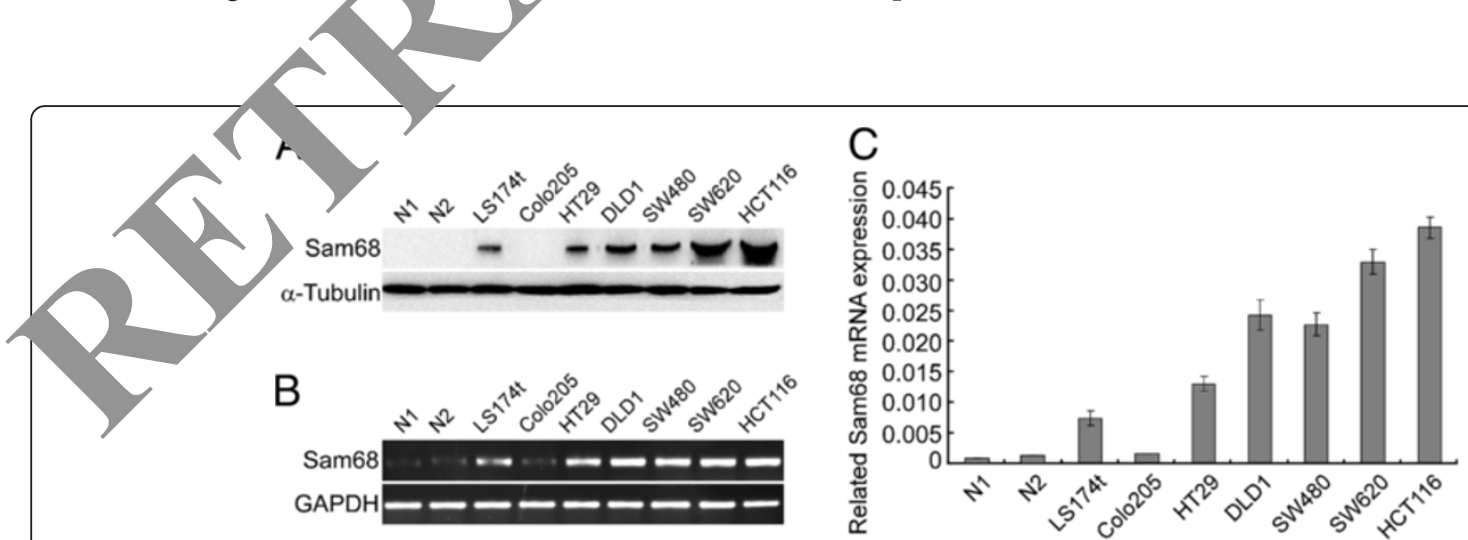

Figure 1 Analysis of Sam68 protein and mRNA expression in colorectal cancer (CRC) cell lines and normal intestine tissues. (A) Analysis of Sam68 protein expression in CRC cell lines (LS174t, Colo205, SW480, HT29, HCT116, SW620) and two cases of normal intestine tissues (N1 and N2) by Western blotting. (B) Analysis of Sam68 mRNA expression by RT-PCR. (C) Analysis of Sam68 mRNA expression in CRC cell lines and normal intestine tissues by Q-PCR, the average ratio of Sam68 expression normalized to GAPDH is shown; values are the mean \pm SD of three parallel experiments. 

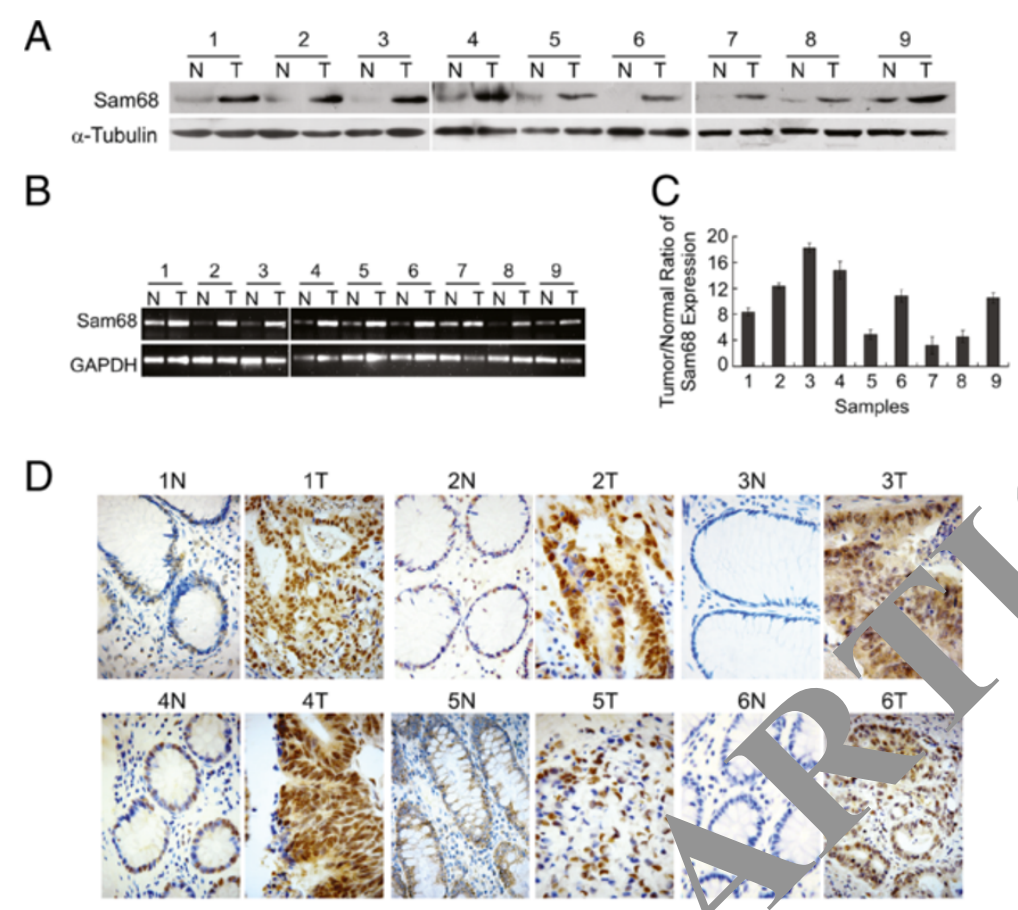

$5 \mathrm{~N}$

$5 T$
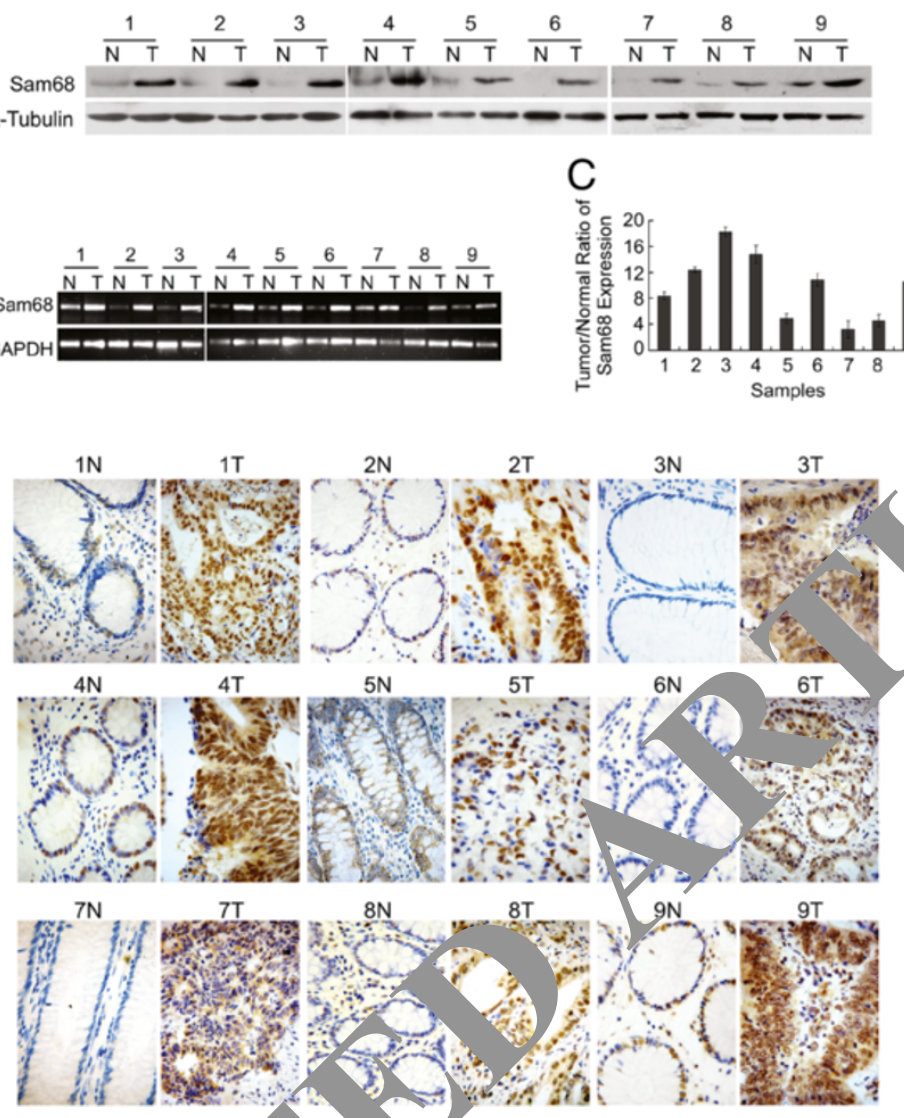

Figure 2 Sam68 is upregulated in primary colorecta' cancer ( $C$ tissues compared with the adjacent normal tissues. (A, B) Analysis of Sam68 mRNA expression in primary CRC tissues (T) ar d paired adjacent normal tissues (N) by RT-PCR (A) and Q-PCR (B). GAPDH was used as loading control. (C, D) Analysis of Sam68 protein e'rpression. vrimary CRC tissues and the paired adjacent normal tissues by Western blotting (C) and immunohistochemistry (D).

metastatic tissues. Negative to mode Sar 68 staining was detected in the adjacent $n$ mal tissues (Figure 3AD); however, positive Sam68 star. was detected in 206 of the $224(92 \%)+a r$ tissues. The tumors could be divided into a 1 S m68 expressing group (104 cases) and a high Sam expressing group (120 cases, Additional file Table St. Additionally, two main patterns of Samb8 pi in expression were observed in the tumors: Cytoplasmic),ocalization (Figure 3E-F) and nuclear ro 7 ion (Figure 3G-J). As shown in Additional file Tab. S1/61.6\% (138/224) of the tumor samples isplà ed nu, rear staining and 38.4\% (86/224) displayed c) rasm staining. Moreover, positive expression of Sam was detected in $81.4 \%(35 / 43)$ of the lymph node metastases (Figure 4) and 65.1\% (28/43) of lymph node metastases were classified as high Sam68 expressing.

\section{Correlations between increased expression of Sam68 and clinical aggressiveness in CRC}

Statistic analyses were performed to evaluate the expression patterns of Sam68 and the clinicopathological features of CRC. As shown in Table 1, the high Sam68 expression level was strongly correlated with poor tumor differentiation $(P=0.033)$, advanced $\mathrm{T}$ stage $(P<0.001)$, $\mathrm{N}$ stage $(P=0.023)$, and distant metastasis $(P=0.033)$ in this cohort of 224 cases of CRC. In addition, high expression level of Sam68 was significantly associated with the nuclear localization of Sam68 $(P=0.012)$. Moreover, Nuclear localization of Sam68 correlated significantly with tumor differentiation $(P=0.002)$ and advanced T stage $(P=0.021)$. These observations suggest that increased expression of Sam68 or nuclear localization of Sam68 was closely associated with aggressive phenotypes of CRC.

Sam68 is associated with poor prognosis in CRC patients In univariate Cox regression analysis, tumor differentiation, $\mathrm{T}$ stage, $\mathrm{N}$ stage and distant metastasis were significant prognostic factors in this cohort of CRC patients (Additional file 2: Table S2; $P<0.001$ ). KaplanMeier survival analysis demonstrated that patients with low levels of Sam68 expression had significantly longer median survival than patients with low Sam68 expression (Figure 5A, upper panel; 71 vs. 51 months; $P=$ 


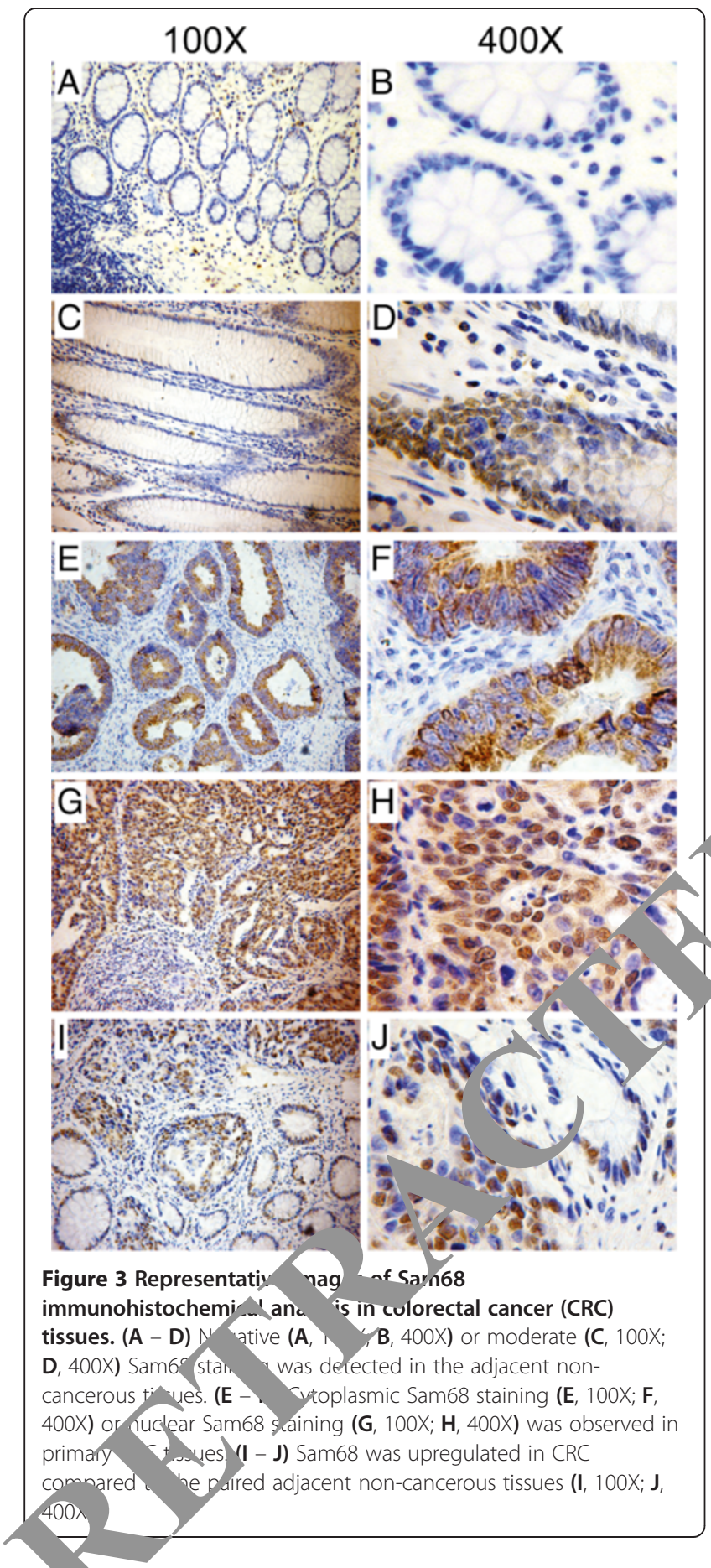

0.02 Jg-rank test). The 5-year survival rate for patients with low Sam68 expression was 70\% (95\% confidence interval, 0.609-0.779), compared to 54\% (95\% confidence interval, 0.448-0.635) for patients with high Sam68 expression.

Next, we analyzed the relationship between the expression of Sam68 in metastatic lymph nodes and survival. Kaplan-Meier analysis indicated that the expression level of Sam68 in the metastatic lymph nodes had a significant impact on survival (Figure 5B; $P=0.029$, log-rank test), as the median overall survival time of patients expressing low levels of Sam68 in the metastatic lymph nodes was significantly longer than patients expressing high levels of Sam68 in the metastatic lymph nodes (log-rank test, $P=0.029$ ).

We also analyzed the prognostic value of the ubcellular localization of Sam68 in CRC. Spearman's , correlation revealed that nuclear localization of Sam in CRC tumors correlated significantly wir orer survival (Spearman Rho -0.232, $P=0.001$ ). Nuditio ' $1 \mathrm{~V}$, KaplanMeier survival analysis confirme that the n,edian survival time for patients with Sam nucle r localization was significantly shorter than tien. ith Sam68 cytoplasmic localization (Fic are 50 , 4 vs. 73 months, $P=$ 0.024, log-rank test). Th -year sy.rvival rate for patients with Sam68 cytoplasmic lo ization was 70\% (95\% confidence interva1, 0. 9-0.77\%), compared to 54\% (95\% confidence in vo patients with Sam68 nuclear lo ization. The Sam68 expression level, subcellula alization of Sam68, pathological stage and $\mathrm{N}$ stage were lo, ntified as independent prognostic factors for overall survival in CRC in multivariate survival an. is (Additional file 3: Table S3 and Additional file 4: Table 4).

rurchermore, in the subgroups of CRC patients withou distant metastasis (M0) or with well/moderately differentiated tumors, both the Sam68 expression level (Figure 6A and C) and subcellular localization of Sam68 (Figure 6E and G) correlated significantly with overall survival. However, no such correlations were observed in the subgroup of patients with distant metastasis or poorly differentiated tumors (Figure 6B,D,F and H).

\section{Discussion}

Sam68 is a substrate of the oncogenic Src kinase, which is often activated in human cancers [4]. Previous researches suggested that two opposing functions of Sam68 were reported in different cellular contexts. On one hand, a few studies indicated that Sam68 acted as a tumor suppressor. For example, Sam68 deficiency resulted in neoplastic transformation of murine NIH3T3 fibroblasts. Reduction of Sam68 was associated with anchorage-independent growth, defective contact inhibition, and the ability to form metastatic tumors in nude mice [31], while overexpression of Sam68 in NIH-3 T3 fibroblasts led to both cell cycle arrest and apoptosis [21]. On the other hand, a large proportion of recent reports demonstrated that Sam68 played an oncogenic role. Sam68 knockdown in polyoma middle T-antigen (PyMT) oncogene transformed cell lines delayed tumorigenesis and metastasis formation in nude mice [25]. Busà $\mathrm{R}$ and colleagues have demonstrated that Sam68 was upregulated in prostate cancer at both protein and 


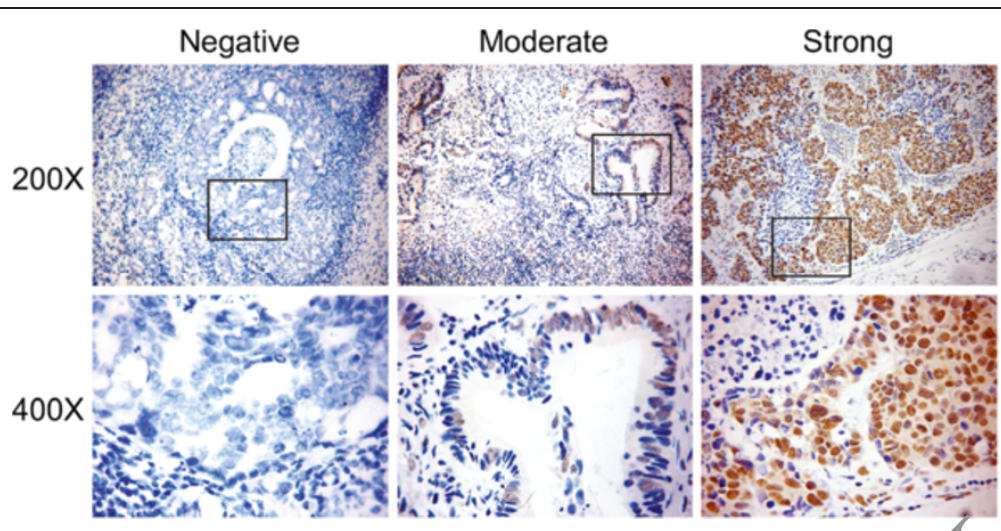

Figure 4 Immunohistochemical analysis of Sam68 expression in metastatic lymph node tissues from cr acta -ar, (RC) patients. Negative, moderate or strong Sam68 staining was observed in CRC metastatic lymph node tissues.

Table 1 Correlation between clinicopathologic features and Sam68 expression

\begin{tabular}{|c|c|c|c|c|c|c|c|}
\hline \multirow[t]{2}{*}{ Characteristics } & \multicolumn{2}{|c|}{ Sam68 levels } & \multirow{2}{*}{$\begin{array}{c}P \\
\text { values }\end{array}$} & \multicolumn{2}{|c|}{ 68 localization } & \multirow{2}{*}{$\begin{array}{c}\mathbf{R} \\
\text { values }\end{array}$} & \multirow{2}{*}{$\begin{array}{c}P \\
\text { value }\end{array}$} \\
\hline & Low & High & & Nu lrar & Cytoplasm & & \\
\hline \multicolumn{8}{|l|}{ Age } \\
\hline$\leq$ mean $(56)$ & 50 & 56 & & 66 & 40 & & 0.848 \\
\hline$>$ mean (56) & 54 & 64 & & 72 & 46 & & \\
\hline \multicolumn{8}{|l|}{ Gender } \\
\hline Male & 61 & & & 76 & 51 & & 0.535 \\
\hline Female & 43 & & & 62 & 35 & & \\
\hline \multicolumn{8}{|l|}{ Histology } \\
\hline Columnar adenocarcinoma & 79 & 102 & & 110 & 71 & & 0.733 \\
\hline Mucinous adenocarcinoma & 14 & 1) & 0.083 & 19 & 6 & & \\
\hline Others & & 7 & & 9 & 9 & & \\
\hline \multicolumn{8}{|l|}{ Differentiation } \\
\hline Well and moderate & & 86 & 0.033 & 97 & 76 & & 0.002 \\
\hline Poor & & 34 & & 41 & 10 & & \\
\hline \multicolumn{8}{|l|}{ T stage } \\
\hline $1-$ & 27 & 13 & & 18 & 22 & & 0.021 \\
\hline 3 & 58 & 64 & $<0.001$ & 77 & 45 & & \\
\hline 4 & 19 & 43 & & 43 & 19 & & \\
\hline & 68 & 59 & 0.023 & 72 & 55 & & 0.072 \\
\hline & 27 & 48 & & 50 & 25 & & \\
\hline 2 & 9 & 13 & & 16 & 6 & & \\
\hline \multicolumn{8}{|l|}{ Distant metastasis } \\
\hline 0 (no) & 78 & 74 & 0.033 & 89 & 63 & & 0.173 \\
\hline 1 (yes) & 26 & 46 & & 49 & 23 & & \\
\hline \multicolumn{8}{|l|}{ Sam68 localization } \\
\hline Nuclear & 55 & 83 & 0.012 & & & & \\
\hline Cytoplasm & 49 & 37 & & & & & \\
\hline
\end{tabular}



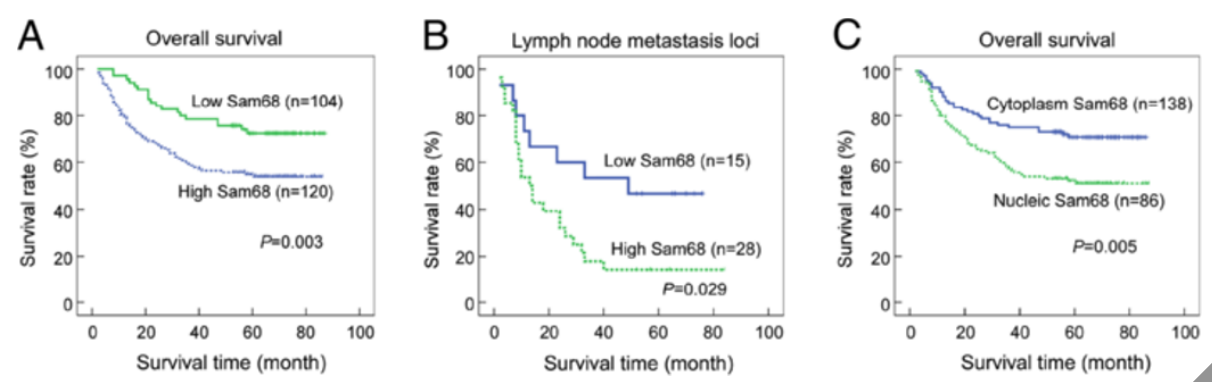

Figure 5 Influence of Sam68 expression on overall survival in colorectal cancer (CRC). (A) Kaplan-Meier curves show ng th. vatient with high Sam68 expression had poorer overall survival than patients with low Sam68 expression; analysis of 224 primary CR tissues (P $=3)$. (B) Kaplan-Meier curves showing that patients with high Sam68 expression in metastatic lymph node tissues had poc er overall survival than patients with low Sam68; analysis of 43 metastatic lymph node tissues $(P=0.029)$. (C) Kaplan-Meier curves showing th vatients vith nuclear Sam68 expression had poorer overall survival than patients with cytoplasmic Sam68 expression; analysis of 224 a ary ues $(P=0.005)$.

mRNA levels. Additionally, downregulation of Sam68 in prostate cancer cells delayed cell cycle progression and reduced the proliferation rate [23]. Sam68 is also upregulated and its upregulation is correlated with shorter survival rates in breast cancer, cervical cancer, renal cell carcinoma $[24,27,28]$. The present study demonstrated that Sam68 was elevated in CRC tissues and the high Sam68 expression level was significantly correlated with the characteristics of aggressive CRC (including poor differentiation of tumors, advanced $\mathrm{T}$ stage, lymph node involvemen $\angle$ and distant metastasis ${ }^{\prime}$ Addition $1 / 1 /$, high Sam68 expression level was a sigr ficar predictor of poor prognosis in CRC patients. Thus, rouns raised the evidence that suggested that Sam68 ight promote development and progression o . of Sam68 in human cancer.

Cam68 is ubiquitously expressed protein and resides in b cytoplasm and nuclei [2]. Posttranslational modiicatic is of Sam68, such as phosphorylation and methyta. 1 , can affect its subcellular localization, interaction

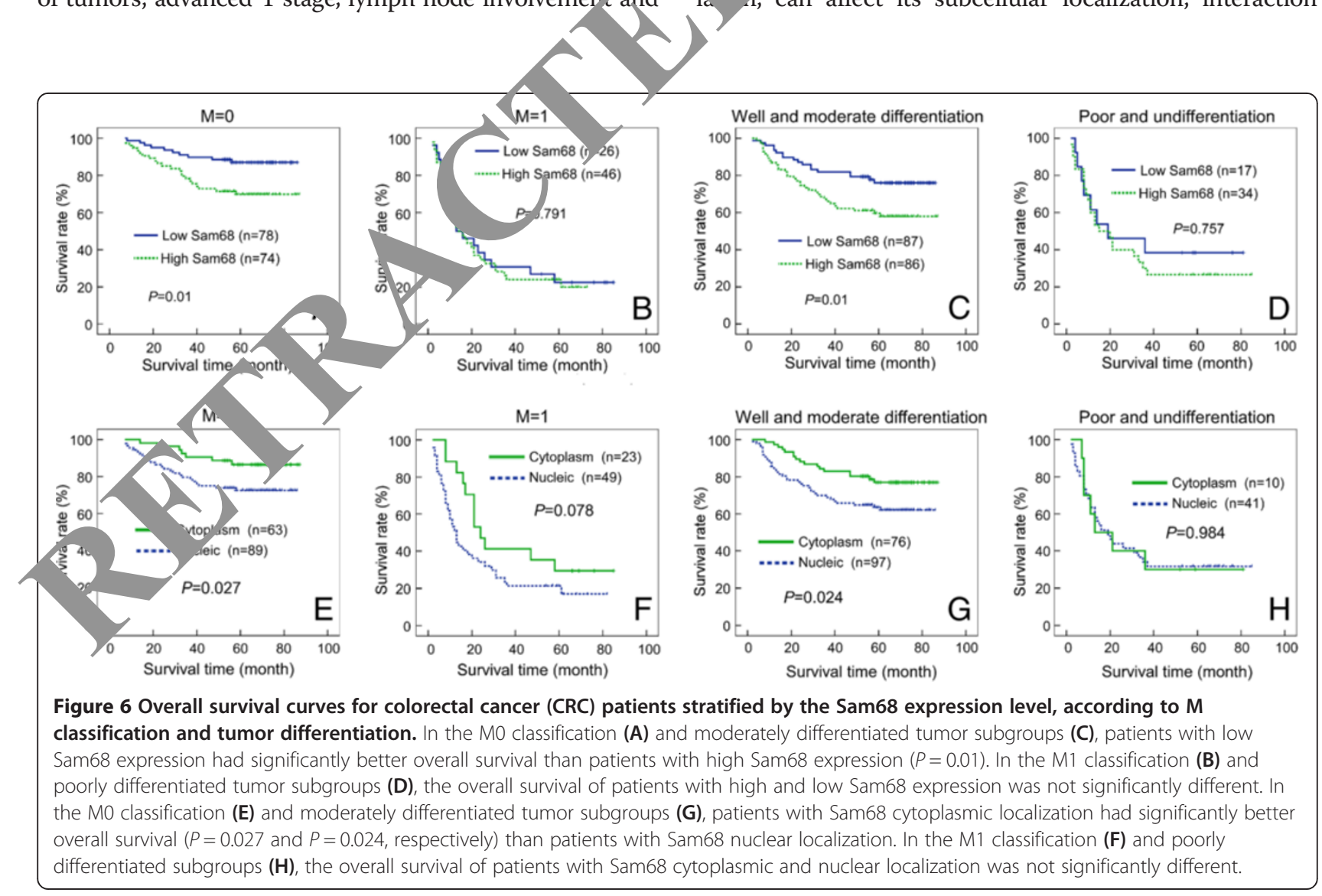


with signaling proteins, as well as affinity for target RNAs [2,15,32-35]. In most cells, Sam68 predominantly resided within the nucleus and is involved in gene transcription, alternative splicing, and nuclear export [12-19]. Sam68 has been observed to exist in dynamic nuclear foci termed Sam68 nuclear bodies (SNBs), also called stress nuclear bodies [12,36]. Genes regulated by Sam68 include CD44, Bcl-xl, Sgce, SMN2, SF2/ASF, Cyclin D1, and so on, which are all involved in oncogenesis [6,14-19]. In the present study, Sam68 was found to localize to both the nuclei and cytoplasm of cancer cells. It is particularly noteworthy that the subgroup of patients with advanced clinical stage CRC often exhibited nuclear localization of Sam68, while CRC patients with well differentiated or early stage tumors often displayed cytoplasmic Sam68 staining. In addition, patients with cytoplasmic Sam68 localization had a better clinical outcome than patients with Sam68 nuclear localization. These researches suggested that nuclear Sam68 might play a dominant role in oncogenesis of CRC. However, distinguished from our results, cytoplasmic localization of Sam68 was significantly correlated with cancer progression and poor prognosis in human renal cell carcinoma and breast cancer [24,27]. It could be due to the functions of Sam68 in multiple signaling pathways, since it can be expressed in both the cytoplasm and nucleus. In the cytoplasm, Sam68 interacts with sign 11 ing molecules such as Src, Grb2, Grap [7-11] and sti, at s oncogenic pathways, including the epidermaro gro $h$ factor pathway, ERK and AKT pathways 7,38]. 1, renal cell carcinoma and breast cancen the $\mathrm{O}$ genic role of Sam68 was closely associated with its act, ation of Akt/GSK-3 $\beta$ pathway [24,27]. Ta en together, these researches suggested that cytopla ic ayd nuclear localization of Sam68 might ntribute to neoplastic transformation or tumor progress, hrough different molecular mechanisms lifferent cancer types or cellular contexts.

This study proydes 4 first evidence to indicate that both high exp r ion leve and nuclear localization of Sam68 correlate 5 . ificantly with invasiveness and aggressiveness characte, stics in CRC, and poorer survival of CRC ti t. ts. Taken together, this study suggests that

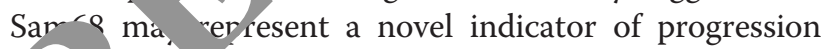
nd p ognosyo in CRC.

\section{Con sions}

In conclusion, Sam68 was upregulated in primary human CRC, and high Sam68 expression levels in CRC were associated with the clinical features of aggressive disease and poorer patient prognosis. Nuclear localization of Sam68 in CRC was identified as an independent predictor of poor prognosis. However, further characterization of the mechanisms by which Sam68 is involved in the transformation and progression of human CRC is required.

\section{Additional files}

Additional file 1: Table S1. Clinicopathologic variables for patient

Additional file 2: Table S2. Univariate Cox regression analysis of potential prognostic factors for CRC patients.

Additional file 3: Table S3. Multivariate Cox regression analysis or Sam68 levels and other potential prognostic factors for CRC

Additional file 4: Table S4. Multivariate Cox regression analys

Sam68 localization and other potential prognostic factors for CRC patients.

\section{Competing interests}

The authors declare that they have no compe interest

\section{Authors' contributions}

WTL participated in the design the study dyafted the manuscript. JLL and ZGW carried out the exp ris of cell cy, ure and molecular biology. LS supported the statistical ar alysis. " $C$ and TTL supported the evaluation of the immunohistoche results. $\lambda$ and XTC participated in collecting the clinical samples. BS an YQD participated in the design of the study. All authors read and ap, ver manuscript.

\section{Acknowleds onts}

This study wa su, dhe Natural Science Foundation of China (No.

30901791, 811, 0555); Nedical Science and Technology Research Fund Projects of Guar adong Province(N0.A2011199); Guangdong Provincial Science loundation of China (No. S2012010009643); Zhu Jiang Scien Technology New Star Foundation in Guangzhou city (2012046). ho. details

${ }^{1}$ Dy, artment of Pathology, Nanfang Hospital, Southern Medical University, uangzhou, Guangdong 510515, China. ${ }^{2}$ State Key Laboratory of Oncology in Southern China, Department of Experimental Research, Sun Yat-sen University Cancer Center, Guangzhou, Guangdong 510060, P.R. China. ${ }^{3}$ Department of Pathology, School of Basic Medical Sciences, Southern Medical University, Guangzhou 510515, China. ${ }^{4}$ State Key Laboratory of Oncology in South China, Department of Medical Oncology, Sun Yat-sen University Cancer Center, Guangzhou, Guangdong 510060, China. ${ }^{5}$ Department of Gastroenterology, the Second Affiliated Hospital, University of South China, HengYang, Hunan 421000, China.

Received: 25 August 2012 Accepted: 2 August 2013

Published: 9 August 2013

\section{References}

1. Weitz J, Koch M, Debus J, Hohler T, Galle PR, Buchler MW: Colorectal cancer. Lancet 2005, 365(9454):153-165

2. Lukong KE, Richard S: Sam68, the KH domain-containing superSTAR. Biochim Biophys Acta 2003, 1653(2):73-86.

3. Taylor SJ, Shalloway D: An RNA-binding protein associated with Src through its $\mathrm{SH} 2$ and $\mathrm{SH} 3$ domains in mitosis. Nat 1994, 368(6474):867-871.

4. Fumagalli S, Totty NF, Hsuan JJ, Courtneidge SA: A target for Src in mitosis. Nat 1994, 368(6474):871-874.

5. Bielli P, Busa R, Paronetto MP, Sette C: The RNA-binding protein Sam68 is a multifunctional player in human cancer. Endocr Relat Cancer 2011, 18(4):R91-R102.

6. Richard S, Torabi N, Franco GV, Tremblay GA, Chen T, Vogel G, Morel M, Cleroux P, Forget-Richard A, Komarova S, et al: Ablation of the Sam68 RNA binding protein protects mice from age-related bone loss. PLOS Genet 2005, 1(6):e74.

7. Paronetto MP, Venables JP, Elliott DJ, Geremia R, Rossi P, Sette C: Tr-kit promotes the formation of a multimolecular complex composed by Fyn, PLCgamma1 and Sam68. Oncogene 2003, 22(54):8707-8715.

8. Huot ME, Brown CM, Lamarche-Vane N, Richard S: An adaptor role for cytoplasmic Sam68 in modulating Src activity during cell polarization. Mol Cell Biol 2009, 29(7):1933-1943. 
9. Derry JJ, Richard S, Valderrama Carvajal H, Ye X, Vasioukhin V, Cochrane AW, Chen T, Tyner AL: Sik (BRK) phosphorylates Sam68 in the nucleus and negatively regulates its RNA binding ability. Mol Cell Biol 2000, 20 (16):6114-6126.

10. Sanchez-Margalet $V$, Najib S: Sam68 is a docking protein linking GAP and PI3K in insulin receptor signaling. Mol Cell Endocrinol 2001, 183(1-2):113-121.

11. Fusaki N, Iwamatsu A, Iwashima M, Fujisawa J: Interaction between Sam68 and Src family tyrosine kinases, Fyn and Lck, in T cell receptor signaling. J Biol Chem 1997, 272(10):6214-6219.

12. Chen T, Boisvert FM, Bazett-Jones DP, Richard S: A role for the GSG domain in localizing Sam68 to novel nuclear structures in cancer cell lines. Mol Biol Cell 1999, 10(9):3015-3033.

13. Lin Q, Taylor SJ, Shalloway D: Specificity and determinants of Sam68 RNA binding. Implications for the biological function of $\mathrm{K}$ homology domains. J Biol Chem 1997, 272(43):27274-27280.

14. Matter $\mathrm{N}$, Herrlich $\mathrm{P}$, Konig H: Signal-dependent regulation of splicing via phosphorylation of Sam68. Nat 2002, 420(6916):691-695.

15. Paronetto MP, Achsel T, Massiello A, Chalfant CE, Sette C: The RNA-binding protein Sam68 modulates the alternative splicing of Bcl-x. J Cell Biol 2007 176(7):929-939.

16. Chawla G, Lin CH, Han A, Shiue L, Ares M Jr, Black DL: Sam68 regulates a set of alternatively spliced exons during neurogenesis. Mol Cell Biol 2009, 29(1):201-213

17. Paronetto MP, Cappellari M, Busa R, Pedrotti S, Vitali R, Comstock C, Hyslop T, Knudsen KE, Sette C: Alternative splicing of the cyclin D1 protooncogene is regulated by the RNA-binding protein Sam68. Cancer Res 2011, 70(1):229-239.

18. Valacca C, Bonomi S, Buratti E, Pedrotti S, Baralle FE, Sette C, Ghigna C, Biamonti G: Sam68 regulates EMT through alternative splicing-activated nonsense-mediated mRNA decay of the SF2/ASF proto-oncogene. J Cell Biol 2010, 191(1):87-99.

19. Pedrotti S, Bielli P, Paronetto MP, Ciccosanti F, Fimia GM, Stamm S, Manley $J$, Sette C: The splicing regulator Sam68 binds to a novel exonic splicing silencer and functions in SMN2 alternative splicing in spinal muscu'ar atrophy. Embo J 2010, 29(7):1235.

20. Babic I, Cherry E, Fujita DJ: SUMO modification of Sam68 enhances ability to repress cyclin D1 expression and inhibits its abili y to induc apoptosis. Oncogene 2006, 25(36):4955-4964.

21. Taylor SJ, Resnick RJ, Shalloway D: Sam68 exerts separá, le et on cell cycle progression and apoptosis. BMC Cell Biol 200\%, J.5.

22. Barlat I, Maurier F, Duchesne M, Guitard E, Tocq B, Schweighoffer F: A role for Sam68 in cell cycle progression antas ized by a pliced variant within the KH domain. J Biol Chem 1997, 272(6, 9-3132

23. Busa $R$, Paronetto MP, Farini $D$, Pieranterzi $E$, Botti , cilini DF, Attisani $F$ Vespasiani G, Sette C: The RNA-binding in Sam68 contributes to proliferation and survival of human prostat Ler cells. Oncogene 2007, 26(30):4372-4382

24. Song L, Wang L, Li Y, Xior $\mathrm{H}, \mathrm{W}$ J, Li J, LI M: Sam68 up-regulation correlates with, and its a tumourigenicity of oreast ca rells. J Pathol 2010, 222(3):227-237.

25. Richard S, Vogel uot ME, Gu Muller WJ, Lukong KE: Sam68 haploinsuffic ncy vs onset of mammary tumorigenesis and metastasi Oncogene 27(4):548-556.

26. Rajan D. Gavghan L, Dalg,esh C, El-Sherif A, Robson CN, Leung HY, Elliott DJ: $\mathfrak{n}$ c ti of ene expression by the RNA-binding protein Sam68 in cancer. $\mathrm{em} S$ C Trans 2008, 36(Pt 3):505-507. Y, Liu TJ, Huang QD, Zhi Yu CP, Ig Y, Liu TJ, Huang QD, Zhao XH, Huang H, Tu H, Jiang S, $\mathrm{Zh}$ Y $\mathrm{Y}$ et al: Sam68 expression and cytoplasmic localization is with lymph node metastasis as well as prognosis in patients early-stage cervical cancer. Ann Oncol 2012, 23(3):638.

28. Zh,ng Z, Li J, Zheng H, Yu C, Chen J, Liu Z, Li M, Zeng M, Zhou F, Song L: Expression and cytoplasmic localization of SAM68 is a significant and independent prognostic marker for renal cell carcinoma. Cancer Epidemiol Biomarkers Prev 2009, 18(10):2685-2693.

29. Liao WT, Wang X, Xu LH, Kong QL, Yu CP, Li MZ, Shi L, Zeng MS, Song LB: Centromere protein $\mathrm{H}$ is a novel prognostic marker for human nonsmall cell lung cancer progression and overall patient survival. Cancer 2009, 115(7):1507-1517.

30. Livak KJ, Schmittgen TD: Analysis of relative gene expression data using real-time quantitative PCR and the 2(-Delta Delta $C(T)$ ) Method. Methods 2001, 25(4):402-408.
31. Liu K, Li L, Nisson PE, Gruber C, Jessee J, Cohen SN: Neoplastic transformation and tumorigenesis associated with sam68 protein deficiency in cultured murine fibroblasts. J Biol Chem 2000, 275(51):40195-40201.

32. Sette C: Post-translational regulation of star proteins and effects on their biological functions. Adv Exp Med Biol 2010, 693:54-66.

33. Sette C, Messina V, Paronetto MP: Sam68: a new STAR in the male fertility firmament. J Androl 2010, 31:66-74.

34. Lukong KE, Larocque D, Tyner AL, Richard S: Tyrosine phosphe vlation of sam68 by breast tumor kinase regulates intranuclear locaíza cell cycle progression. J Biol Chem 2005, 280(46):38639-38647.

35. Cote J, Boisvert FM, Boulanger MC, Bedford MT, Richard C Sam68 RNA b. protein is an in vivo substrate for protein arginine $\mathbb{N}^{-}$, hyltransfe ase 1. Mol Biol Cell 2003, 14(1):274-287.

36. Denegri $M$, Chiodi I, Corioni $M$, Cobianchi $F$ kiva $S$, Biamon stressinduced nuclear bodies are sites of accur ulation of pre-miRNA processing factors. Mol Biol Cell 2001/12(1 502-3514

37. Martin-Romero C, Sanchez-Margalen Yuma tin activates PI3K and MAPK pathways in human per " hera. od mononuclear cells: possible role of Sam68. Cell Immunol 001, 212(2).

38. Locatelli A, Lange CA: Me re vors induc Sam68-dependent cell migration by activation of alter extracellular signal-regulated kinase family members. Them 2011, $6(24): 21062-21072$.

doi:10.1186/14/1--

Cite this article as: Lic al.: High expression level and nuclear localizatio $\mathrm{Sam} 68$ ar ssociated with progression and poor prognosis i_tal cancer. BMC Gastroenterology 2013 13:126.

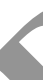

\section{Submit your next manuscript to BioMed Central and take full advantage of:}

- Convenient online submission

- Thorough peer review

- No space constraints or color figure charges

- Immediate publication on acceptance

- Inclusion in PubMed, CAS, Scopus and Google Scholar

- Research which is freely available for redistribution 